\title{
Design Analysis on Planting Patterns and Relationships Used in Artists' Gardens at the Seoul Garden Show
}

\author{
Park, Eun-Yeong ${ }^{1^{*}}$ \\ 1 Dept. of Environmental Landscape Architecture, Joongbu University \\ *Corresponding Author, Email: eypark@joongbu.ac.kr
}

Received: May 15, 2017; Accepted: April 10, 2018

Keywords: Network Analysis, Seoul Garden Show, Patterns of the Plants

\begin{abstract}
This study aims to analyze the design of the artist gardens at the Seoul Garden Show based on planting patterns by identifying the relationships among plants and species of plants. The author selected 10 artworks as the study subject, preferentially targeting cases with clear drawings and those having at least 20 herbaceous plants among the gardens created for the Seoul Garden Show held at the World Cup Park in Sangam-dong, Seoul. The author used Net Miner 4.0, a social network analysis program, to examine the direct connection among plantings. Furthermore, the study analyzed the degree of connection and centrality, which could be helpful in explaining the types of plant materials and characteristics of planting patterns among the index that were available for the design analysis. According to the results of this analysis, I derived the plants of the upper groups based on the degree and degree centrality. Simultaneously, the upper groups were designated up to the third rank. An in-depth study of the characteristics and meanings of the plants of the upper groups was then undertaken. To summarize the results of the study, chrysanthemum was found to be the plant with the highest degree centrality, followed by willow herb. In the case of planting with the highest degree for each artwork, approximately 10 species or more are connected. However, it was difficult to find a similar pattern of planting method among the artworks. This is probably due to the characteristics of the Seoul Garden Show because they had to present a powerful theme in a small area and use appropriate plant concepts to meet the goal. However, chrysanthemum types, Shrubs, herbaceous plants with distinctive leaves, and herbaceous plants with distinctive flowers exhibited a higher degree of connection than the other plants.
\end{abstract}

\section{INTRODUCTION}

Seoul launched the Seoul Garden Show to revive aging parks as part of an urban regeneration measure (Park, 2015). The World Cup Park located in Sangam-dong, Seoul, has held the Seoul Garden Show since 2015 with the aim of promoting garden culture in citizens' daily life as well as revitalizing it as a space for garden, design, and even art. In particular, various plants have been used for garden culture in the city and experimental designs (Zoh, 1994). 
In addition to the Seoul Garden Show, a number of artists who were invited at the Gyeonggi Garden Exhibition, the International Horticulture Goyang Korea, as well as the RHS Chelsea Flower Show and the International Garden Festival of Chaumont sur Loire from foreign countries have created their unique gardens and showcased them during the exhibition show (Park, 2015; Jeong \& Jeong, 2016). However, in terms of creating a garden, plant usage is more likely to recognized as an exclusive design preference of artists or regarded as demonstrating their unique sense (Hobhouse, 2002). In reality, herbaceous plants constitute a large proportion of the plants used in the Garden Show, or herb plantations are frequently created without any drawings. This is because it is difficult to draw every plant relative to the garden's extensive scale or because the plantation often suddenly changes on site due to the conditions of supply and demand of plants.

Nonetheless, plant designing complies with specific principles and characteristics of plant use (Lord, 1995; Waymark, 2003). As the Garden Show continues, it is necessary to explore the underlying reasons for why the artists who created the gardens used certain plants or chose different patterns for planting them. However, demonstrating the relationships between plants and their patterns has been difficult because previous studies have been limited to identifying the frequency and trends of herbaceous flower planting (Hitchmough and Fleur, 2006). Therefore, examining plant patterns and relationships among plants in actual gardens would be meaningful, in particular, to address repetitive issues of plant supply and demand at the annually hosted garden expositions, preservation, and management, as well as data collection of planting design.

Accordingly, this study aims to analyze the design based on planting patterns by identifying the relationships among plants and species of plants used in the artist gardens at the Seoul Garden Show. This study uses a clearly differentiated analysis method from the existing analyses that have focused on the characteristics of individual plants. Essentially, plant usage in a garden is determined by the manner in which plants are combined. It aims to identify the relationships between plants, the arrangement of plants in the network, and the structuring of their relationships in the overall network pattern. The author believes that this study would help garden designers identify the potential value of using plants that have so far not been highlighted in planting design.

\section{LITERATURE REVIEW}

\subsection{Social network analysis}

Unlike traditional statistical techniques that involve analysis based on the assumption that individual objects are independent, social network analysis assumes that individual objects are inter-dependent and attempts to identify structural patterns among the objects and the characteristics of the network. In addition, social network analysis explains the characteristics of objects that account for the system based on their relationships (Barnes, 1954; Scott, et al., 2008). Social network analysis is expressed using nodes that indicate the meaning of the subject and links that indicate the relationships between the nodes. This allows for analyzing relationships among objects from a macroscopic viewpoint and identifying and schematizing structural patterns that become apparent in the relationships ( $\underline{\text { Scott, 2000) }}$. 
Degree refers to the number of links connected to nodes. It serves as the most important indicator to assess the importance of nodes and to analyze the overall structure of the network. Centrality is an indicator of each node's relative power and importance in the network system (Freeman, 1978), which comprises degree centrality, betweenness centrality, and closeness centrality. Degree centrality is measured by the sum of directly connected objects, and betweenness centrality is an indicator to measure the level of intermediary roles among objects in the network. Closeness centrality, unlike degree centrality, calculates distances between all objects both directly and indirectly connected to the network (Wasserman and Faust, 1994), influential nodes within the network can be identified by degree centrality measured based on their degree. The author used this indicator to identify influential nodes from the plants and analyze planting patterns and relationships for each artwork.

\subsection{Planting design research}

Research on planting design has been primarily centered around the design philosophies of some outstanding artists such as William Robinson (Simo, 1985), Gertrude Jekyll (Kerrigan, 2009), Foerster (2005), and Piet Oudolf (Kingsbury, N. and Oudolf, 2010), and the planting intentions exhibited in specific gardens created by them. Additionally, many studies on plants have focused on ecological aspects (Sepahi, 2000; Mahmoud \& Omar, 2015; Cerra and Crain, 2016) or individual properties of plants without attempting to study the aesthetic aspects of plants and their relationships and patterns (Malgorzata, 1991). In particular, plant studies at garden fairs have been themed around the frequencies and trends of the planting of flowering plants with virtually no empirical studies on how to choose plants when creating gardens in the real world (Hitchmough \& Fleur, 2006). In this sense, there is a need to understand what plant artists focus on when creating gardens and how they structuralize patterns and relationships by combining plants.

\section{MATERIALS AND METHODS}

\subsection{Study scope}

As the subject of the study, the author selected 10 artworks, as shown in Table 1 and Figure 1, preferentially targeting cases that have clear drawings and those having at least 20 herbaceous plants among the gardens created for the Seoul Garden Show held at the World Cup Park in Sangam-dong, Seoul.

The target of the research included four artworks created in 2015 and six created in 2016. In terms of the scope, the research focused more on studying the relationships rather than individual attributes or simply analyzing the frequency of plant usage. In order to identify the planting patterns of each artwork, the author conducted an in-depth study on the relationships and degrees of connection among plants. Thus, even though various kinds of plants may have been used in the artworks, with the aim of identifying the relationships between the plants, the author limited the scope of the study to the cases that allowed to grasp these relationships given that certain species were gathered in a group. 


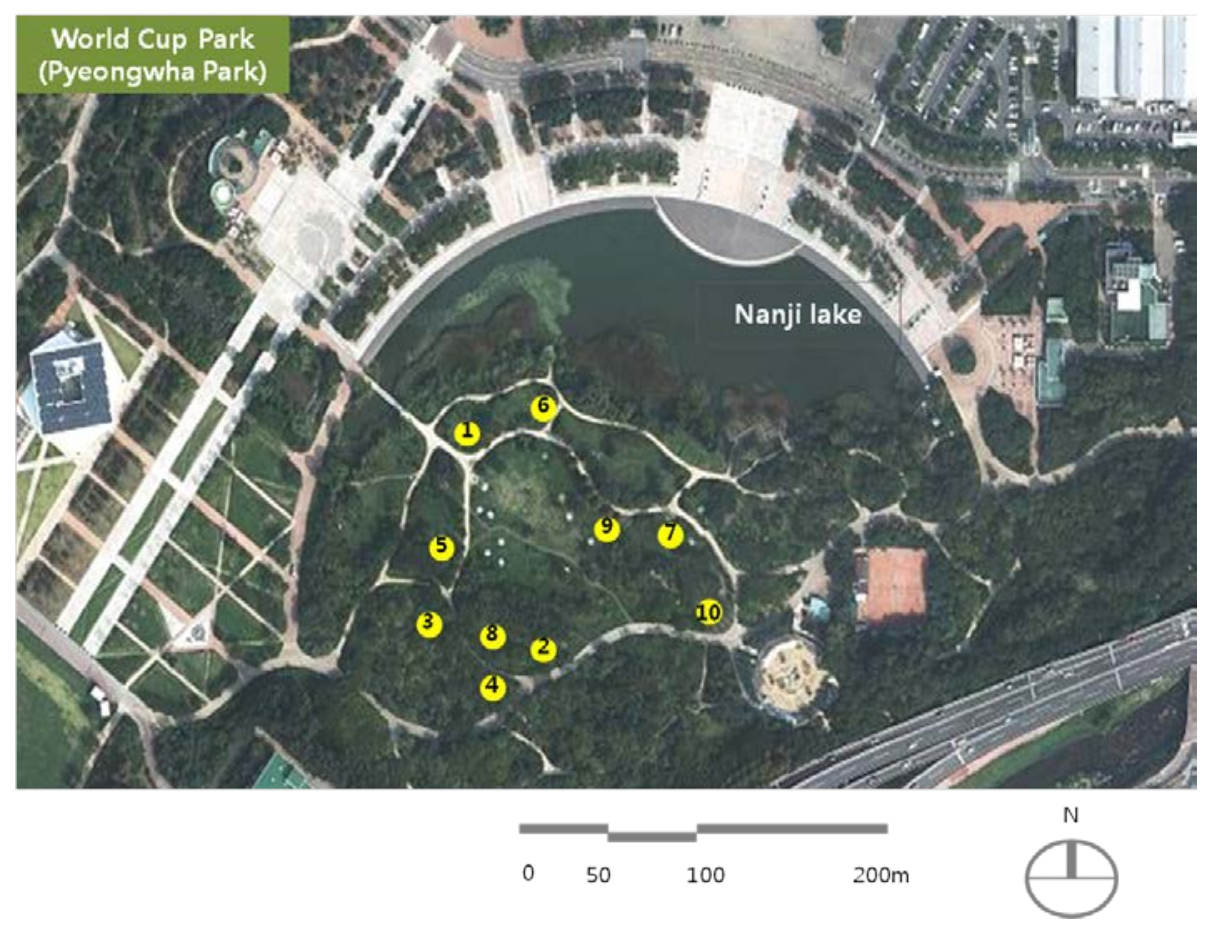

Figure 1. Map of the study site

Table 1. Types of 10 artworks for case studies

\begin{tabular}{clc}
\hline Artwork & \multicolumn{1}{c}{ Garden types } & Year created \\
\hline 1 & Interpretation of nature & 2015 \\
2 & Play / Active & 2016 \\
3 & Cottage / Daily & 2016 \\
4 & Rest / Seating & 2016 \\
5 & Rest / Seating & 2015 \\
6 & Play / Active & 2015 \\
7 & Natural / Wild & 2016 \\
8 & Rest / Seating & 2016 \\
9 & Tradition & 2015 \\
10 & Interpretation of nature & 2016 \\
\hline
\end{tabular}

\section{2 $\quad$ Research method}

This study adopted network analysis, which is widely used in the field of social studies and communications, to analyze the relationships of plants used at the Seoul Garden Show. The author used the Net Miner 4.0, a social network analysis program, to examine the direct connection between plantings. Furthermore, the study analyzed the degree of connection and centrality that could help explain the types of plant materials and characteristics of planting patterns among the index that were available for the analysis.

The author used the degree to analyze the direct connections of the nodes. The degree value indicates the number of nodes that are connected to the node. Degree centrality analyzes the centrality of the network structure based on the degree. This allowed for calculating the level of proximity of the nodes with respect to each other. According to the results of this analysis, the author derived the plants of the upper groups based on the degree (of connection) and the degree centrality (Provan \& Milward, 1995; 
Freeman, 2008). Simultaneously, the upper groups were designated up to the third rank. The characteristics and meanings of the plants of the upper groups were then studied in-depth.

Currently, the relational concept of men has been adopted for the social network analysis in most cases. However, a network refers to certain relationships connecting multiple people, organizations, objects, etc. This study expanded the boundaries of such a network to the relationships among the plants used in landscaping. The relationships among the plants will be modeled as nodes and links, which then becomes a methodology for quantitative analysis on the topological structure and diffusion/ evolution process. Here, the relationships refer to interaction, or so called, relational property, and interactions among analysis units and not individual attributes

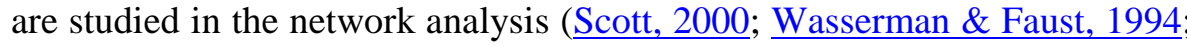
Borgatti \& Halgin, 2011).

\subsection{Field surveys for collecting presence data}

This study used the drawings created by artists and interviews with participants of the Seoul Garden Show as data. It analyzed the drawings of planting focusing on herbaceous plants. When the planting differed from the drawings, actual planting cases were primarily used for the research. A total of four visual observation examinations and photo interpretations for the years 2015 and 2016 were studied twice as supplementary data.

\section{RESULTS}

\subsection{Identification of degree centrality and degree of planting pattern for each artwork}

The researcher calculated the degree centrality values to identify the level of connection among the plantings corresponding to each artwork for ten artworks and arranged the results in a table according to the ranks. In addition, the author organized the planting patterns of each artwork in the form of a figure. The size of the nodes reflects the degree, and the author classified into seven groups, namely grasses, vine types, sedums, chrysanthemum types, shrubs, herbaceous plants with distinctive leaves, and herbaceous plants with distinctive flowers by using different colors.

As illustrated by Table 2, artwork 1 had 15 nodes and used 3 chrysanthemum type plants, 3 shrubs, 2 kind of grass, 2 herbaceous plants with distinctive leaves, 1 vine type, and 4 herbaceous plants with distinctive flowers. Siberian chrysanthemum (Dendranthema zawadskii) had a degree of 12 and had the highest degree centrality at 0.86. Fountain grass (Pennisetum alopecuroides) and winged euonymus (Euonymus alatus) had a degree of 8 and the second-highest degree centrality at 0.57. Showy stonecrop (Hylotelephium spectabile) had a degree of 6 , and its degree centrality was the third-highest at 0.5 .

Table 2. Degree centrality and degree of planting for Artwork 1 Artwork 1

ID

Dendranthema zawadskii Pennisetum alopecuroides Euonymus alatus

$\begin{array}{ll}\text { Centrality } & \text { Degree } \\ 0.86 & 12 \\ 0.57 & 8 \\ 0.57 & 8\end{array}$


Artwork 1

Hylotelephium spectabile

0.5

6

This artwork had pink flowers such as chrysanthemum and showy stonecrop at the center, and fountain grass and Mongolian false needlegrass (Stipa tenuissima) were combined against their background to express a rich and soft texture. With regard to the planting on the upper part, winged euonymus with the good color of autumnal colors indicated a high degree centrality. Compared to other artworks, this artwork can be characterized by a spatial framework with the use of shrubs, as shown in Figure 2.

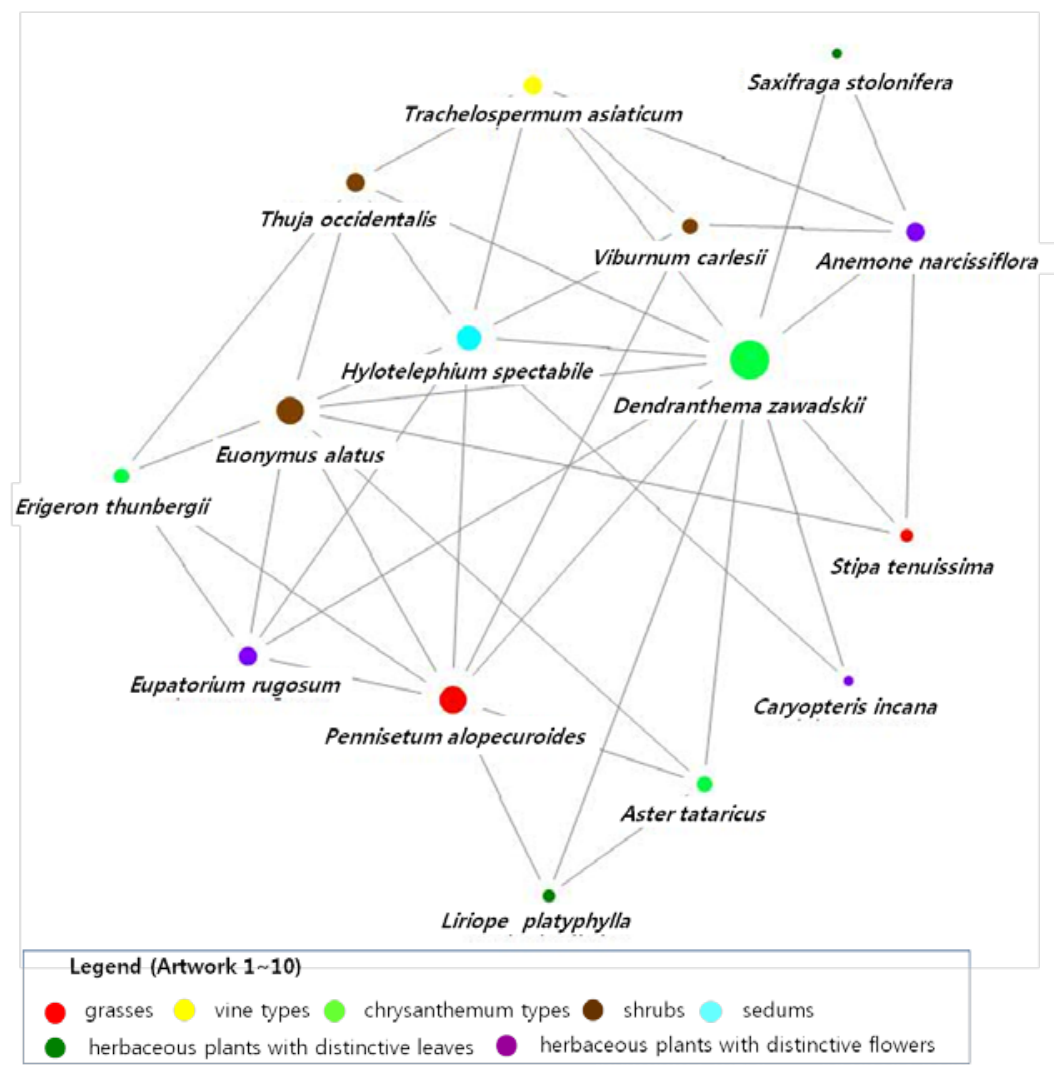

Figure 2. Planting pattern of Artwork 1

Table 3 reads that artwork 2 used 20 nodes with 5 shrubs, 1 grass type, 5 herbaceous plants with distinctive leaves, 1 vine type, and 8 herbaceous plants with distinctive flowers. Blueberry (Vaccinium corymbosum) had the highest degree at 8 , and the highest degree centrality at 0.44 . American arborvitae (Thuja occidentalis) had a degree of 6 with the second-highest degree centrality at 0.33 . Willow herbs (Epilobium angustifolium), Allium senescens L., climbing bagabane (Trachelospermum asiaticum), red-bark dogwood (Cornus alba), and Japanese spurge (Pachysandra terminalis) had a degree of 5 , and the third-highest degree centrality at 0.28 .

Table 3. Degree centrality and degree of planting for Artwork 2

\section{Artwork 2}

ID

Vaccinium corymbosum

Centrality

Thuja occidentalis

0.44

Degree

Trachelospermum asiaticum

0.33

0.28

0.28

Epilobium angustifolium

0.28

8

6

5

Allium senescens

5 


\begin{tabular}{lll}
\hline Artwork 2 & \\
Cornus alba & 0.28 & 5 \\
Pachysandra terminalis & 0.28 & 5 \\
\hline
\end{tabular}

Figure 3 depicts that artwork 2 had blue berries, whose leaves turn red in the autumn, at the center, and evergreen and American arborvitae were connected to represent a contrast. In addition to this, red-leafed shrubs such as winged euonymus or red-bark dogwood trees were planted. Herbaceous plants with distinctive leaves such as climbing bagabane, Japanese spurge, and Mukdenia rossii were covered, and mid-length pink flowers that are greatly influenced by the wind, for example, willow herbs or Allium senescens L. were planted. Herbs such as mint or rosemary that were not included in other artworks were planted.

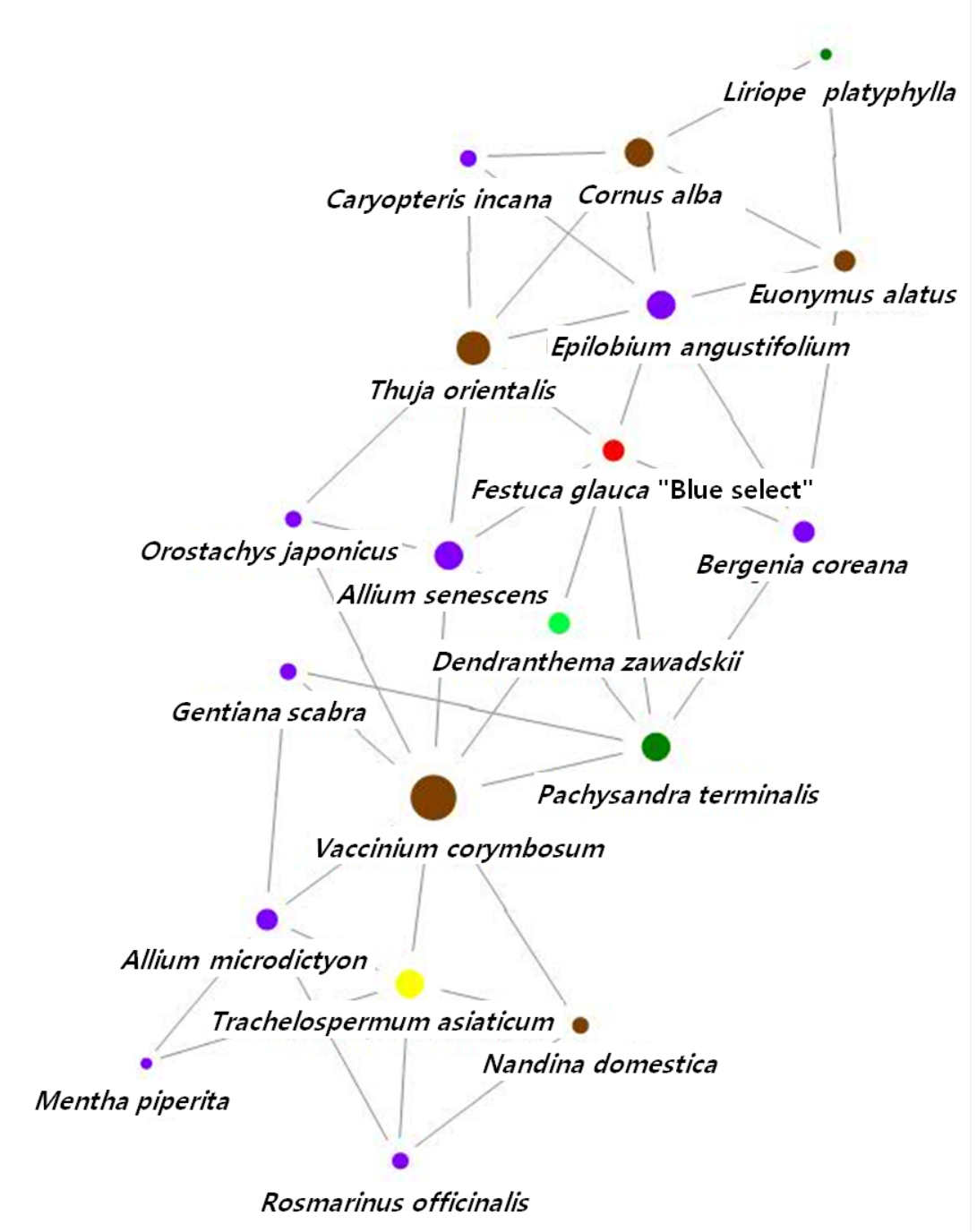

Figure 3. Planting pattern of Artwork 2

As presented in Table 4, artwork 3 used 16 nodes, 3 shrubs, 3 grass types, 2 herbaceous plants with distinctive leaves, 1 vine type, 2 chrysanthemum types, and 5 flowers. Big blue lilyturf (Liriope platyphylla) had a degree of 10, and the highest degree centrality at 0.67. Asters (Aster tataricus) had a degree of 9, and the second-highest degree centrality at 0.6. Cluster-amaryllis (Lycoris radiate), the baby brier (Rosa multiflora), and blueberry had a degree of 6 , and the third-highest degree centrality at 0.4 . 
Table 4. Degree centrality and degree of planting for Artwork 3

Artwork 3

ID

Liriope platyphylla

Aster tataricus

Centrality

Degree

Vaccinium corymbosum

Lycoris radiata

Rosa multiflora

Liriope platyphylla

0.67

10

Aster tataricus

$0.6-9$

$0.4-6$

$0.4 \quad 6$

$0.4 \quad 6$

$0.67-10$

The garden designer of this work mainly tends to design with leaves. Figure 4 shows that the designer expressed centrality by including leaves in the entire framework, and planted pink asters, red cluster-amaryllis, and purple gentian (Gentiana scabra) by connecting these short seasonal species. Uniquely, in this artwork, the designer planted annuals cockscomb (Celosia cristata) along with cluster-amaryllis and Capsicum annuum var. abbreviatum. that were not observed in other works.

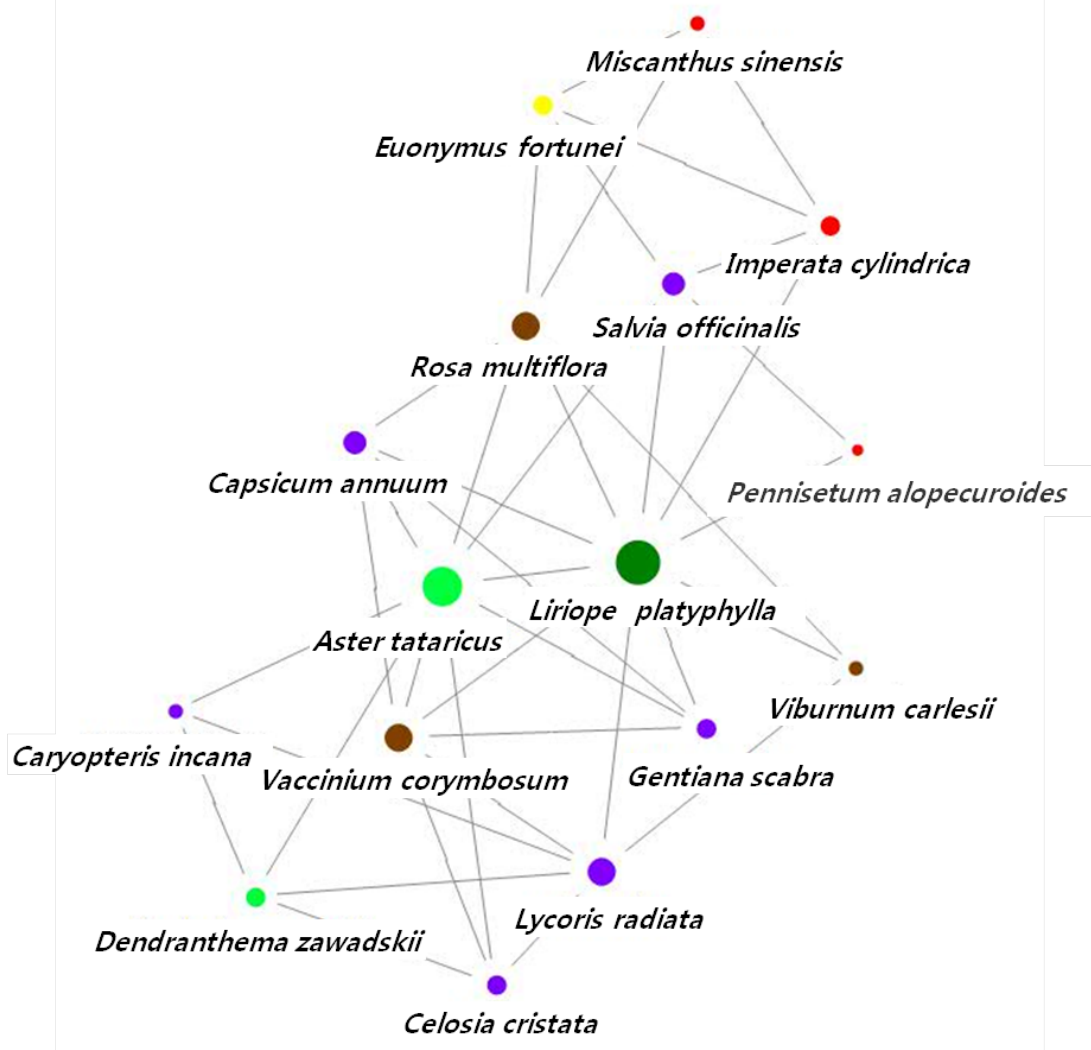

Figure 4. Planting pattern of Artwork 3

Table 5 describes that artwork 4 used 11 nodes in addition to 3 herbaceous plants with distinctive leaves, 1 shrub, 2 grass types, and 5 herbaceous plants with distinctive flowers. Bracken (Pteridium aquilinum) had the highest degree of 7 , and the highest degree centrality of 0.7. Alpine leek (Allium microdictyon), sedge (Carex pendula maxima), and slender bistort (Bistorta alopecuroides) had a degree of 6, and the second- 
highest degree centrality at 0.6. Astilbe (Astilbe rubra) had a degree of 5, and the third-highest degree centrality at 0.5 .

Table 5. Degree centrality and degree of planting for Artwork 4

Artwork 4

ID

Pteridium aquilinum

Allium microdictyon

Centrality

Degree

Carex pendula maxima

Bistorta alopecuroides

Astilbe rubra

0.7

0.6

0.6

0.6

0.5

Pteridium aquilinum

Allium microdictyon

0.6

7
6
6
6
5
7
6

Artwork 4 has a centrality of wild low-height bracken and sedge and herbaceous plants with a roughly textured species. They were connected with broad-leaved alpine leek and vertical scouring rush (Equisetum hyemale), and additionally, pink-colored slender bistort and the astilbe with flowers growing upwards were planted, imparting an exotic feeling. Unlike many other artworks, chrysanthemum types did not appear in Artwork 4 from Figure 5 .

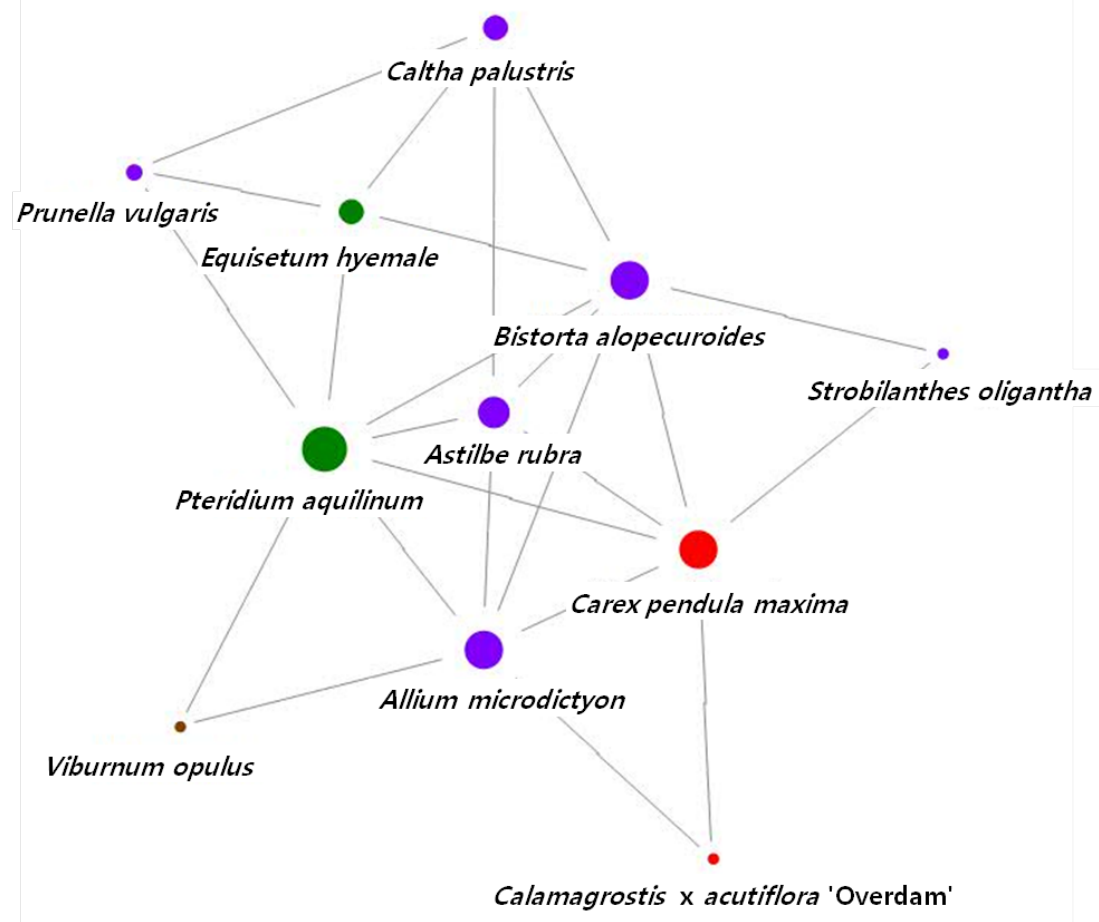

Figure 5. Planting pattern of Artwork 4

Artwork 5 used 17 nodes with 1 shrub, 5 kind of grass, 3 chrysanthemum types, 2 herbaceous plants with distinctive leaves, 1 sedum, and 3 herbaceous plants with distinctive flowers as shown in Table 6. Blue spirea (Caryopteris incana) had the highest level with a degree of 10 and degree centrality of 0.63 , and willow herbs had a degree of 8 and the secondhighest degree centrality at 0.5. Ajania pacifica, windflower (Anemone hupehensis), and flame grass (Miscanthus sinensis) had a degree of 7 and the third-highest degree centrality at 0.44 
Table 6. Degree centrality and degree of planting for Artwork 5

Artwork 5

ID

Caryopteris incana

Epilobium angustifolium

Miscanthus sinensis

Anemone hupehensis

Ajania pacifica

Caryopteris incana

Epilobium angustifolium

\begin{tabular}{ll} 
Centrality & Degree \\
0.63 & 10 \\
0.5 & 8 \\
0.44 & 7 \\
0.44 & 7 \\
0.44 & 7 \\
0.63 & 10 \\
0.5 & 8 \\
\hline
\end{tabular}

Figure 6 depicts that this artwork focused on the herbaceous plants species to enable visitors to feel the wind by planting seasonal and long pink-type flowers such as blue spirea, windflower, and willow herb. The designer added a fluffy texture by linking with flame grass, fountain grass, sedge, pink muhly (Muhlenbergia Capillaris), and Calamagrostis $\mathrm{x}$ acutiflora 'Overdam'. The artwork imparts increased stability by connecting short chrysanthemum type plants such as purple Ajania pacifica, Siberian chrysanthemum, and Korean alpine fleabane (Erigeron thunbergii) with plants with distinctive leaves.

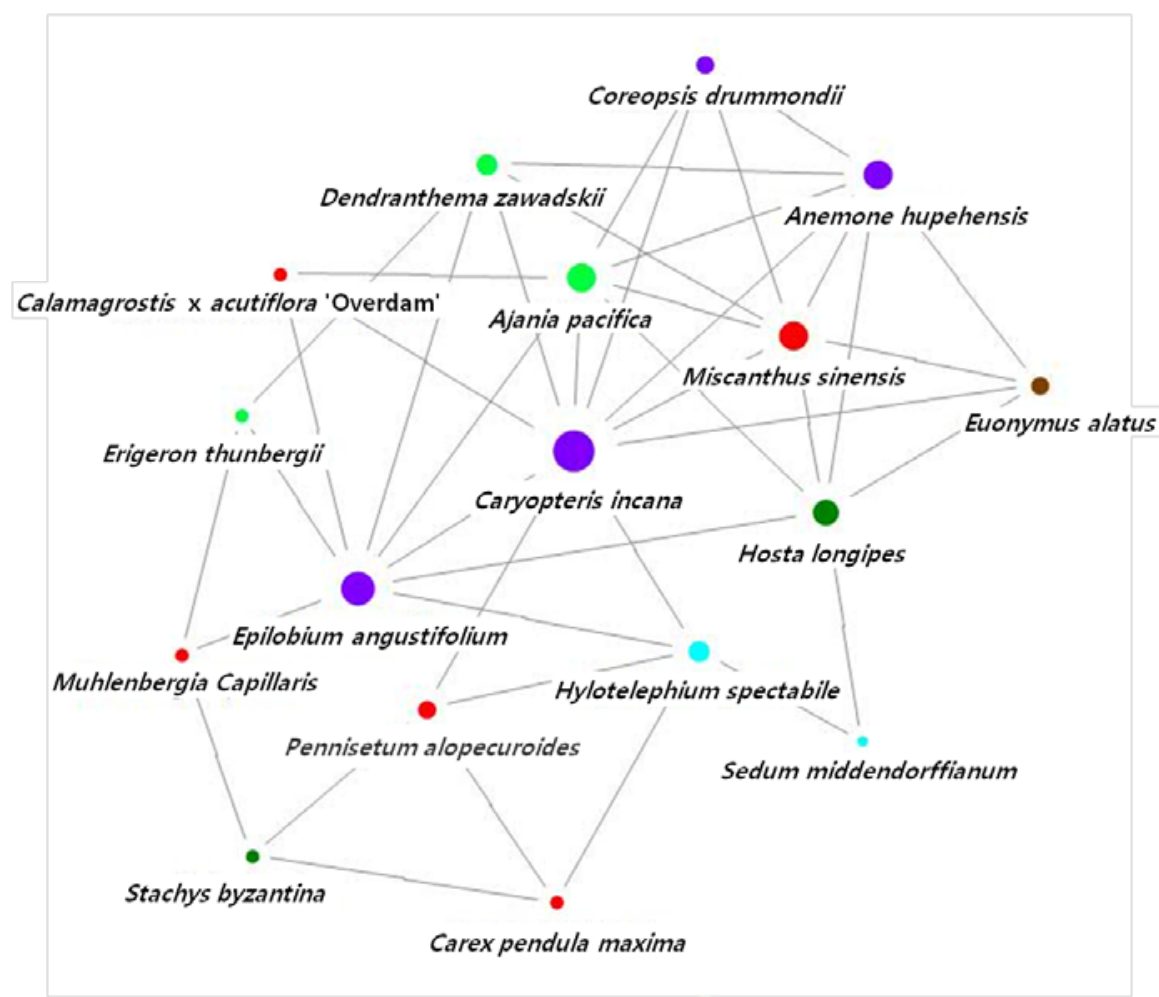

Figure 6. Planting pattern of Artwork 5

As stated in Table 7, artwork 6 used 14 nodes with 3 chrysanthemum types, 4 shrubs, 2 kind of grass, 1 herbaceous plant with distinctive leaves, and 4 herbaceous plants with distinctive flowers. Siberian chrysanthemum had the highest degree of 10 and degree centrality of 0.77 . Miscanthus sinensis 'Morning Light' had a degree of 8 and the second-highest degree centrality of 0.62. Aster, sacred bamboo (Nandina domestica), Korean alpine fleabane, and willow herb had a degree of 7 , and the third-highest degree centrality of 0.54 . 
Table 7. Degree centrality and degree of planting for Artwork 6

Artwork 6

ID

Dendranthema zawadskii

Centrality

Degree

Miscanthus sinensis 'Moring Light'

0.77

10

Epilobium angustifolium

0.62

0.54

Nandina domestica

0.54

Aster tataricus

0.54

Erigeron thunbergii

0.54

Dendranthema zawadskii

0.77

8

7

7

7

7

10

Figure 7 pictures that this artwork has the centrality of purple-colored and short chrysanthemum types such as Siberian chrysanthemum, Korean alpine fleabane, and aster. They are connected with plants with the sacred bamboo of red maple leaves and the shrubs of the evergreen boxwood tree. This is differentiated from other works by linking red and purple directly. Moreover, this artwork expresses the fluffy texture by connecting flame grass with pink colored, long willow herb, Eupatorium rugosum, and windflower.

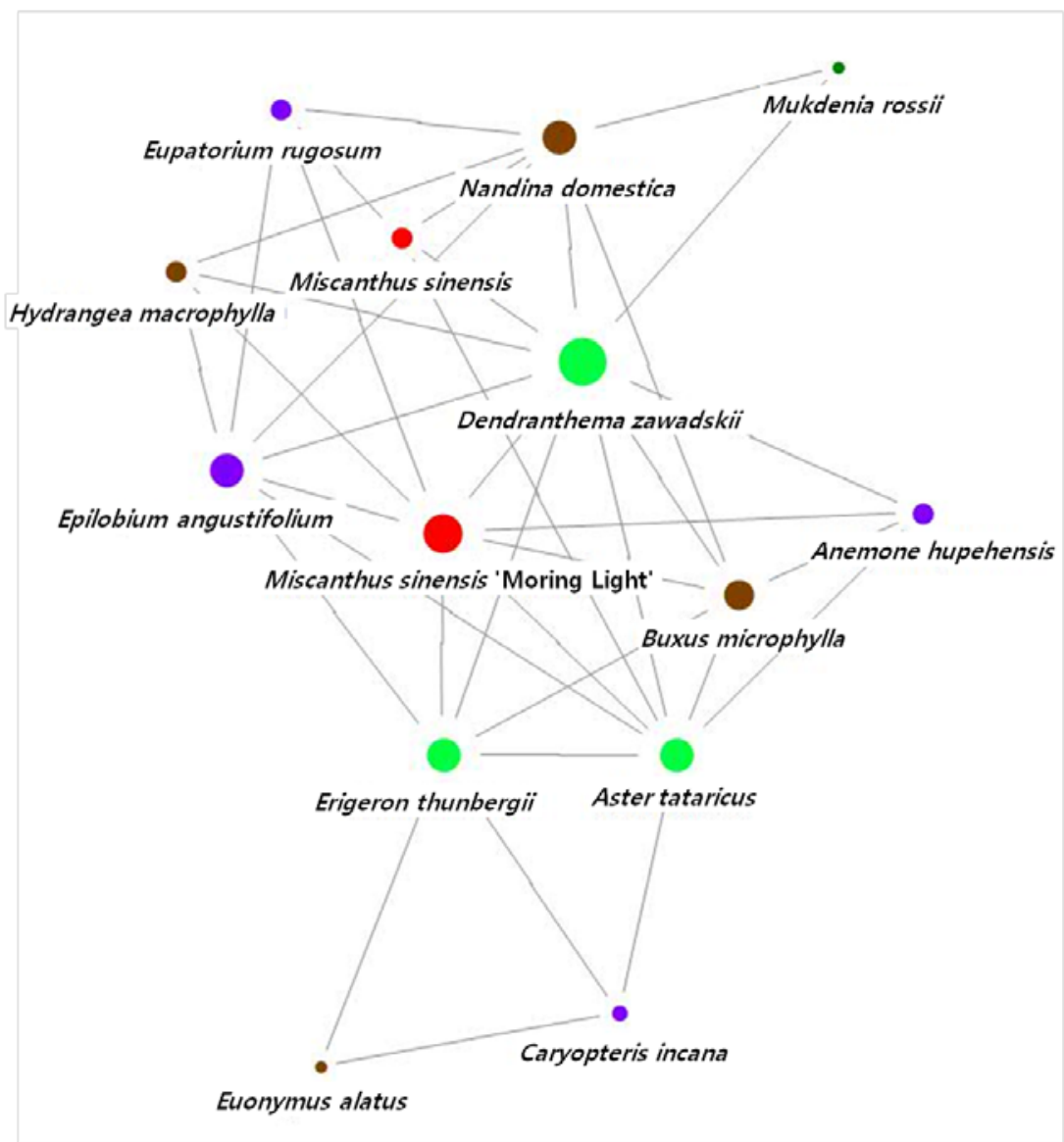

Figure 7. Planting pattern of Artwork 6

Artwork 7 used 13 nodes with 4 kind of grass, 3 herbaceous plants with distinctive leaves, 1 vine type, 2 sedums, 1 chrysanthemum types, and 2 herbaceous plants with distinctive flowers as illustrated by Table 8. Christ plant (Euphorbia milii) had the highest degree of 10 and degree centrality of 0.83, and purple bracted plantain lily (Hosta longipes) had a degree of 8 with the second-highest degree centrality of 0.67 . Imperata cylindrica 'Red Baron', Festuca glauca 'Blue select', willow herb, and Siberian 
chrysanthemum had a degree of 5 with the third-highest degree centrality of 0.42 .

Table 8. Degree centrality and degree of planting for Artwork 7

Artwork 7

ID

Euphorbia milii

Hosta longipes

Dendranthema zawadskii

Festuca glauca ' Blue select'

Imperata cylindrica ' Red Baron'

Epilobium angustifolium

Euphorbia milii

\begin{tabular}{ll} 
Centrality & Degree \\
0.83 & 10 \\
0.67 & 8 \\
0.47 & 5 \\
0.47 & 5 \\
0.47 & 5 \\
0.47 & 5 \\
0.83 & 10 \\
\hline
\end{tabular}

Figure 8 shows that this work's designer focused on the leaves rather than flowers by planting the contrasting colors of red Imperata cylindrica 'Red Baron' and silver Festuca glauca 'Blue select' in purple bracted plantain lily and short Euphorbia milii. Seasonal flowers such as Epilobium angustifolium, Siberian chrysanthemum, and cherry sage (Salvia officinalis) were linked with them. Short-length plants were mainly used extensively, and in particular, orange stonecrop (Sedum middendorffianum) and coastal moss-like stonecrop (Sedum oryzifolium) that were not used in other works were planted.

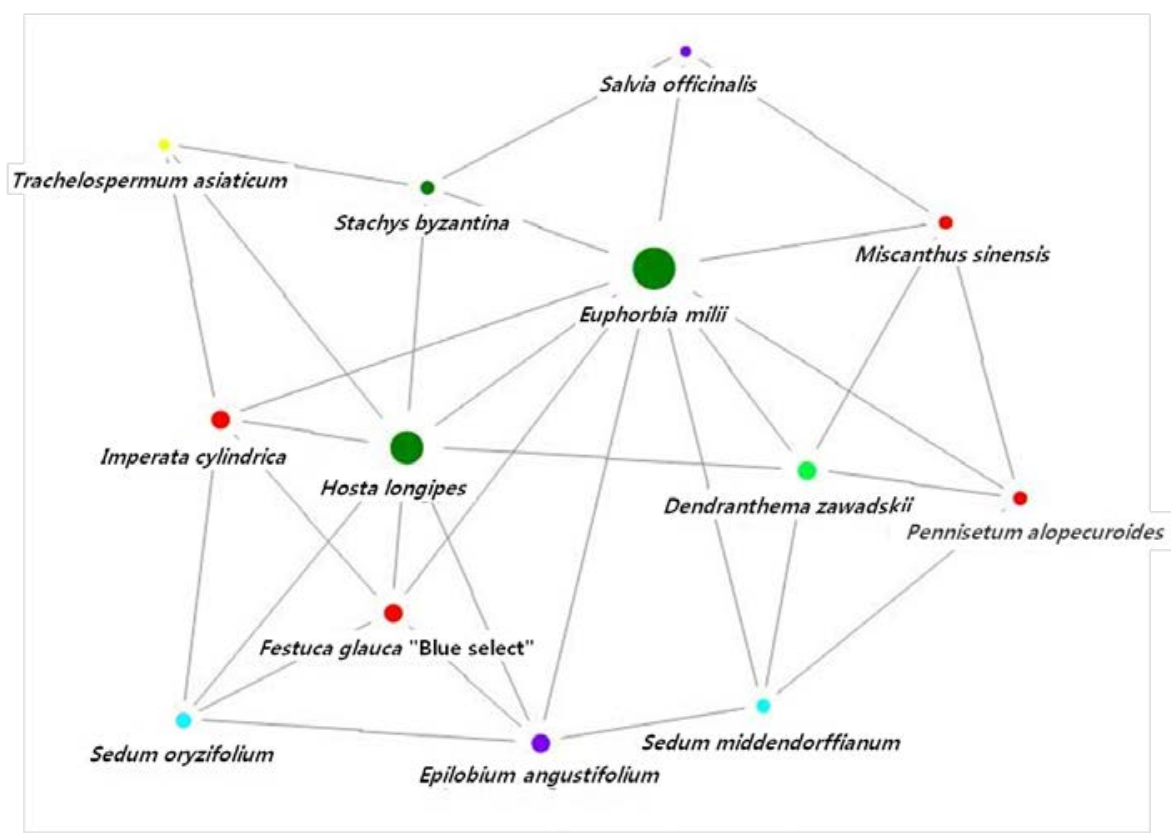

Figure 8. Planting pattern of Artwork 7

Artwork 8 used 18 nodes with 5 shrubs, 4 herbaceous plants with distinctive leaves, 1 vine type, 3 grass types, 1 chrysanthemum type, and 4 herbaceous plants with distinctive flowers. Big blue lilyturf had the highest degree of 9 and degree centrality of 0.53. Hydrangea (Hydrangea macrophylla) had a degree of 8 and the second-highest degree centrality of 0.47. Viburnum rhytidophyllum, Ajania pacifica, and yucca (Yucca gloriosa) had a degree of 6 and third-highest degree centrality of 0.35 , presented in Table 9. 
Table 9. Degree centrality and degree of planting for Artwork 8

Artwork 8

ID

Liriope platyphylla

Centrality

0.53

0.47

Hydrangea macrophylla

Ajania pacifica

Viburnum rhytidophyllum Hemsl.

Yucca gloriosa

Liriope platyphylla

Hydrangea macrophylla
6

$0.35 \quad 6$

$0.35 \quad 6$

$0.53 \quad 9$

From Figure 9, its obviously depicted that this work focused on the vertical and strong leafy plants of big blue lilyturf and yucca, and was planted and linked with the red berries of Viburnum rhytidophyllum, hydrangea with big flowers, Ajania pacifica with unique leaf color, and Spiraea japonica 'Walbuma'. The designer connected grass types, Crocus sativus, and showy stonecrop intermediately.

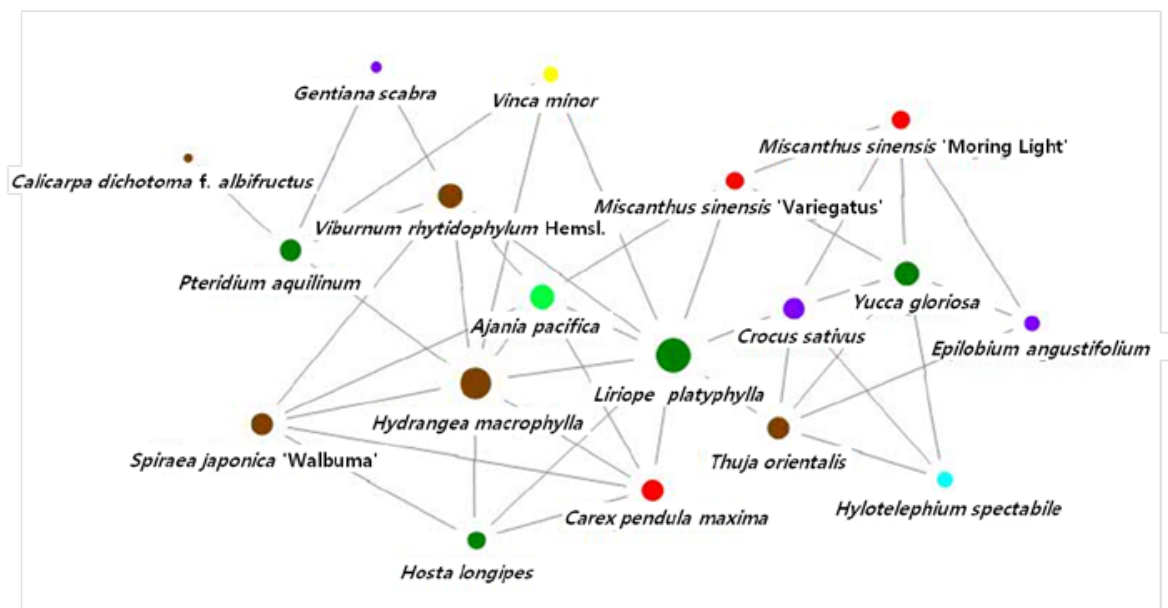

Figure 9. Planting pattern of Artwork 8

Table 10. Degree centrality and degree of planting for Artwork 9

\begin{tabular}{lll}
\hline Artwork 9 & Centrality & Degree \\
ID & 0.45 & 13 \\
Dendranthema zawadskii & 0.28 & 8 \\
Hosta longipes & 0.28 & 8 \\
Caryopteris incana & 0.24 & 7 \\
Epilobium angustifolium & 0.24 & 7 \\
Rudbeckia bicolor Nutt. & 0.45 & 13 \\
Dendranthema zawadskii & 0.28 & 8 \\
Hosta longipes & &
\end{tabular}

Table 10 shows that artwork 9 used 30 nodes, 6 shrubs, 5 kind of grass, 4 herbaceous plants with distinctive leaves, 1 vine type, 1 sedum, 3 chrysanthemum types, and 10 herbaceous plants with distinctive flowers. Siberian chrysanthemum had the highest degree of 13 and degree centrality of 0.45 . Blue spirea and purple bracted plantain lily had a degree of 8 and the second-highest degree centrality of 0.28 . Willow herb and pinewood coneflower (Rudbeckia bicolor Nutt.). had a degree of 7 and the thirdhighest degree centrality of 0.24 .

Figure 10 depicts that the seasonal Siberian chrysanthemum had the most centrality, linking with medium height purple blue spirea and willow herb, and shrubs. Since the yellow pinewood coneflower, grasses, shrubs, 
and trees with distinctive leaves are combined appropriately, its degree centrality is low compared with other works, but the connection rules are well maintained with length, leaves, flower, grasses, etc. Particularly, unlike other works, yellow flowers appeared in the upper group.

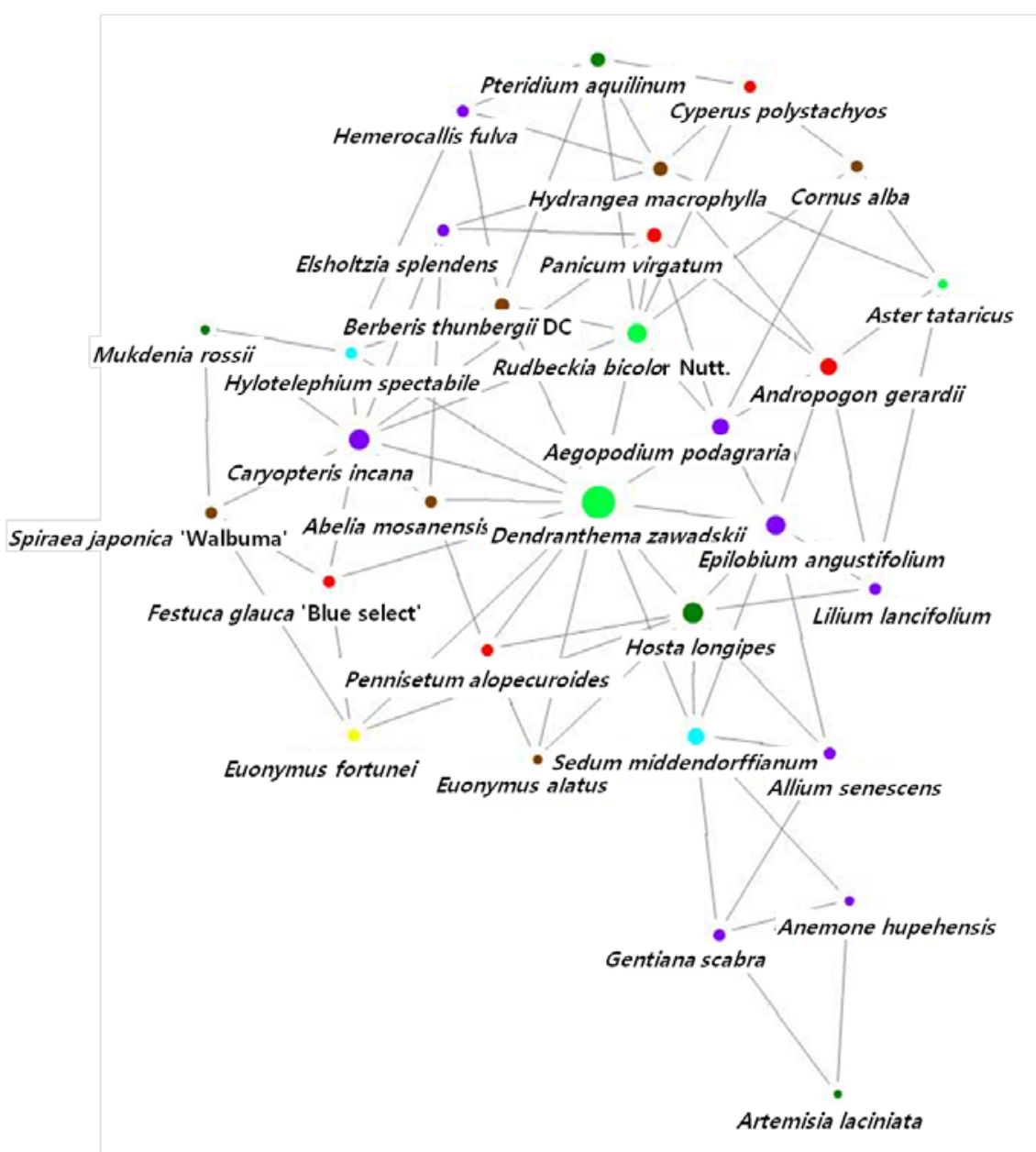

Figure 10. Planting pattern of Artwork 9

Table 11. Degree centrality and degree of planting for Artwork 10

Artwork 10

ID

Dendranthema zawadskii

Anemone hupehensis

Dendranthema zawadskii

Anemone hupehensis

Pennisetum alopecuroides

Dendranthema zawadskii
Pennisetum alopecuroides

$\begin{array}{ll}\text { Centrality } & \text { Degree } \\ 0.87 & 13 \\ 0.53 & 8 \\ 0.47 & 7 \\ 0.87 & 13 \\ 0.53 & 8 \\ 0.47 & 7 \\ 0.87 & 13\end{array}$

Artwork 10 used 16 nodes with 2 shrubs, 4 kind of grass, 2 vine types, 2 herbaceous plants with distinctive leaves, 4 chrysanthemum types, and 2 herbaceous plants with distinctive flowers. Siberian chrysanthemum had the highest level with a degree of 13 and degree centrality of 0.87 . Windflower had a degree of 8 and the second-highest degree centrality of 0.53 . Fountain grass had a degree of 7 with the third-highest degree centrality of 0.47 , by the look of Table 11.

In Figure 11, it is shown that as Siberian chrysanthemum has the highest degree centrality among the 10 artworks, it was connected with grasses of 
the texture influenced by the wind and also has a high degree with pink color and long windflower.

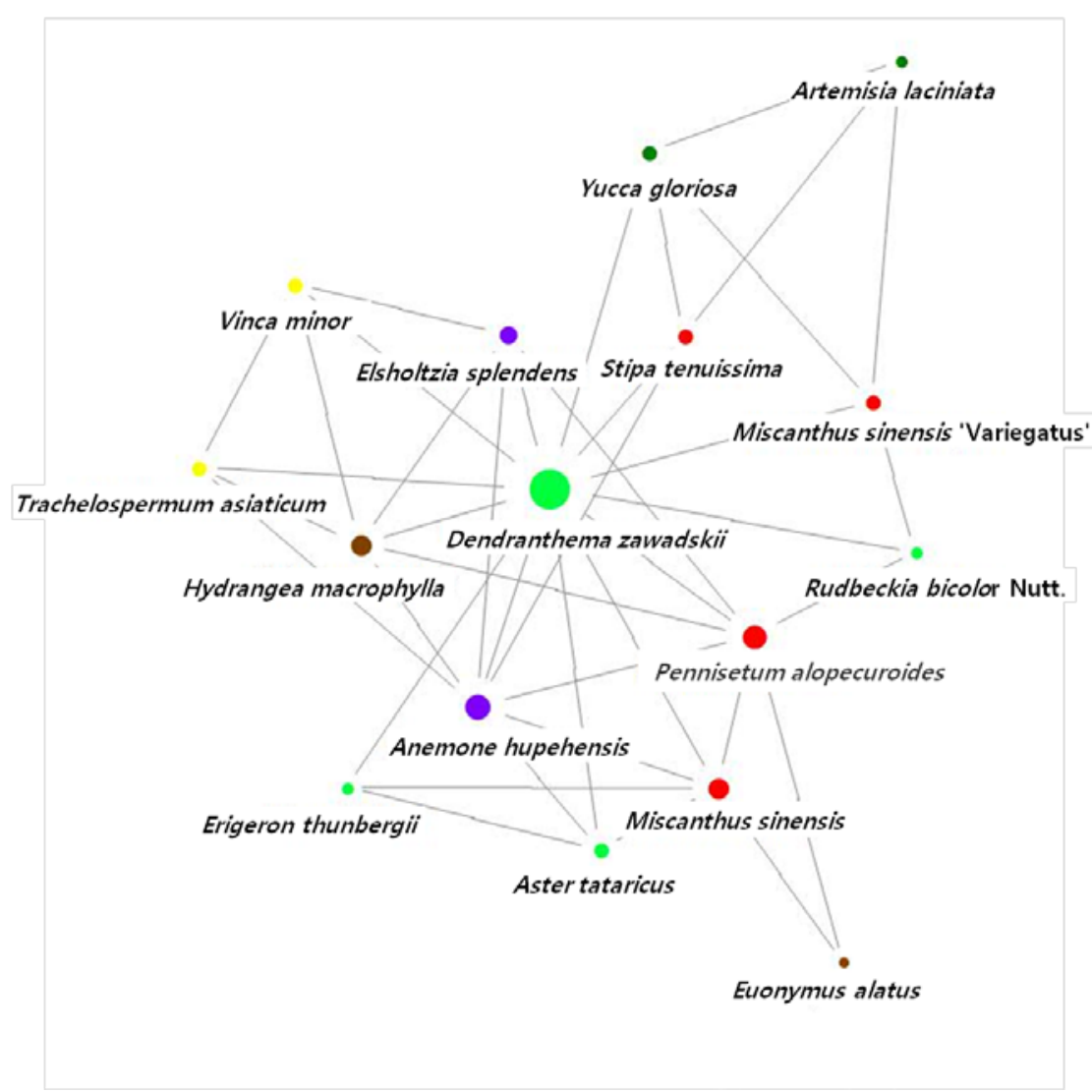

Figure 11. Planting pattern of the Artwork 10

\subsection{Derivation of the upper-level groups in terms of degree centrality and degree of planting pattern by artworks}

The author set up the top three groups based on the analysis results by grouping the upper groups with higher degree centrality and degree, as indicated in Table 12. The plants with the highest degree centrality were Siberian chrysanthemum followed by willow herb. In other words, Siberian chrysanthemum and willow herb were the most influential in the network, and the artists focused on these plants and combined them with other plants when constructing the garden. In the case of planting with the highest degree for each artwork, approximately 10 species or more were found to be connected. However, it was difficult to find a similar pattern of planting method among the artworks. This is probably due to the characteristics of the Seoul Garden Show, because they had to set up a powerful theme in a small area and use appropriate concepts of plants to meet the goal. However, chrysanthemum types, shrubs, herbaceous plants with distinctive leaves, and herbaceous plants with distinctive flowers indicated higher degrees in terms of connections than the other planting. 
Table 12. Selected upper group of degree centrality and degree of planting pattern by artworks

\begin{tabular}{|c|c|c|c|c|c|c|c|c|c|c|}
\hline Rank & $\begin{array}{l}\text { Art } \\
\text { work } \\
1 \\
\end{array}$ & $\begin{array}{l}\text { Art } \\
\text { work } \\
2 \\
\end{array}$ & $\begin{array}{l}\text { Art } \\
\text { work } \\
3 \\
\end{array}$ & $\begin{array}{l}\text { Art } \\
\text { work } \\
4 \\
\end{array}$ & $\begin{array}{l}\text { Art } \\
\text { work } \\
5 \\
\end{array}$ & $\begin{array}{l}\text { Art } \\
\text { work } \\
6 \\
\end{array}$ & $\begin{array}{l}\text { Art } \\
\text { work } \\
7 \\
\end{array}$ & $\begin{array}{l}\text { Art } \\
\text { work } \\
8 \\
\end{array}$ & $\begin{array}{l}\text { Art } \\
\text { work } \\
9 \\
\end{array}$ & $\begin{array}{l}\text { Art } \\
\text { work } \\
10 \\
\end{array}$ \\
\hline 1 & 3 & 22 & 30 & 49 & 25 & 3 & 4 & 30 & 3 & 3 \\
\hline 2 & $\begin{array}{l}2 \\
29\end{array}$ & 24 & 31 & $\begin{array}{l}15 \\
40 \\
54\end{array}$ & 14 & 34 & 8 & 33 & $\begin{array}{l}8 \\
25\end{array}$ & 37 \\
\hline 3 & 46 & $\begin{array}{l}9 \\
14 \\
23 \\
26\end{array}$ & $\begin{array}{l}22 \\
58 \\
60\end{array}$ & 50 & $\begin{array}{l}1 \\
37 \\
43\end{array}$ & $\begin{array}{l}14 \\
17 \\
31 \\
32\end{array}$ & $\begin{array}{l}3 \\
5 \\
7 \\
14\end{array}$ & $\begin{array}{l}43 \\
72 \\
76\end{array}$ & $\begin{array}{l}14 \\
82\end{array}$ & 2 \\
\hline
\end{tabular}

3: Dendranthema zawadskii 22: Vaccinium corymbosum 30: Liriope platyphylla 49: Pteridium aquilinum 25: Caryopteris incana 4: Euphorbia milii 2: Pennisetum alopecuroides 24: Thuja occidentalis 31: Aster tataricus 15: Allium microdictyon 14: Epilobium angustifolium 34: Miscanthus sinensis 'Moring Light' 8: Hosta longipes 33: Hydrangea macrophylla 37: Anemone hupehensis 29: Euonymus alatus 40: Carex pendula maxima 54: Prunella vulgaris 46: Hylotelephium spectabile 9: Trachelospermum asiaticum 50: Astilbe rubra 1: Miscanthus sinensis 43: Ajania pacifica 58: Lycoris radiate 17: Nandina domestica 5: Festuca glauca 'Blue select' 72: Viburnum rhytidophyllum Hemsl. 82: Rudbeckia bicolor Nutt. 23: Allium senescens 60: Rosa multiflora 7: Imperata cylindrica 76: Yucca gloriosa 26: Cornus alba 32: Erigeron thunbergii.

\section{DISCUSSION}

Since the Seoul Garden Show that was held in 2015 and 2016 began in early October, chrysanthemum plants that were the most common in fall were planted. In addition, garden designers linked their plantings with tall shrubs that allowed them to captured the framework of the entire space such as winged euonymus and sacred bamboo with good fall colors. There were also high degrees of purple bracted plantain lily, big blue lilyturf, and bracken that allows visitors to see green leaves, which is the base of the whole space. In the event of the garden show, which needs to attract the attention of visitors, the designers also connected windflower, blue spirea, and willow herb as seasonal flowers.

From the perspective of the design, as for the planting patterns of the artworks, the shrubs with violet and pink flowers as well as the red leaves had the highest degree centrality in terms of color. On the texture side, the rough or wild species and tall plants that are greatly influenced by the wind had high degree centrality. In terms of shape, when the flowers are very small, such as willow herb or chrysanthemum species, racemose inflorescence and vertical flowers had high degree centrality.

Chrysanthemum is the most distributed plant during the Seoul Garden Show, and many artists choose it because it is cheaper and maintenancefriendly, considering the installation cost of the show supporting low funding. Since willow herb is high in plant height with small flowers, it is easy to use wind, and since Piet Oudolf, all 10 artworks use the grasses that are popular worldwide (Kingsbury, N. and Oudolf, 2010). As it matches with the grasses, it appears to have a high degree centrality. The grass is also easy to buy during this season, and since it has a color resembling achromatic color, it can be effectively used as a background planting material. 


\section{CONCLUSIONS}

In order for the Seoul Garden Show to continue to be successful, we need to look at similar patterns of planting methods to understand why artists used these plants. In particular, if the Seoul Garden Show is held in a similar place for a designated period, the discovery of planting patterns may affect the supply and maintenance of plants.

To summarize the results of this design study, chrysanthemum was the plant with the highest degree centrality, followed by willow herb. In the case of planting with the highest degree for each work, approximately 10 species or more were connected. However, it was difficult to find a similar pattern of planting method among the artworks. This is probably due to the characteristics of the Seoul Garden Show, because they had to set up a powerful theme in a small area and use appropriate concepts of plants to meet the goal. However, chrysanthemum types, shrubs, herbaceous plants with distinctive leaves, and herbaceous plants with distinctive flowers indicated higher degree in terms of connection than another planting.

Planting design follows certain principles and characteristics in using plants. However, studying the relationships between plants actually used by artists and their planting patterns is not easy. This study is significant as it employs a clearly differentiated analysis method from existing analyses that focus on the characteristics of individual plants, by examining relationships between plants, their arrangements in the network, and how their relationships are structured in the overall network pattern.

The study has some limitations. Since the plants have grown over the two years since the drawings of the plantings were created, the currently observable plants may be different than those intended at planting owing to natural selection and the growth process.

Future studies will be required to address this limitation and to add further information about the individual characteristics of the plants.

\section{ACKNOWLEDGMENT}

This paper was supported by Joongbu University Research \& Development Fund, in 2018.

\section{REFERENCES}

Barnes, J. A. (1954). "Class and committees in a Norwegian Island Parish", Human Relations, $1(7), 39-58$.

Borgatti, S. P., \& Halgin, D. S. (2011). "On Network Theory", Organization Science, 22(5), $1168-1181$.

Cerra, J. F., \& Crain, R. (2016). "Urban birds and planting design: strategies for incorporating ecological goals into residential landscapes", Urban Ecosystems, 19(4), 1823-1846.

Foerster, M. (2005). Der garten meines vaters Karl Foerster (The garden of my father Karl Foerster), Deutsche verlags-anstalt, München.

Freeman, L. C. (1978). "Centrality in social networks conceptual clarification", Social Networks, 1(3), 215-239.

Freeman, L. C. (2008). Social Network Analysis, Sage publ, London.

Hitchmough, J., \& Fleur, M. de la. (2006). "Establishing North American prairie vegetation in urban parks in northern England: Effect of management and soil type on long-term community development", Landscape and Urban Planning, 78(4), 386-397.

Hobhouse, P. (2002). Flower garden designs, Frances Lincoln Limited, London. 
Jeong, N., \& Jeong, M. (2016). "Planning for Mother’s Garden of Memory in Seoul Garden Festival", Journal of East Asian Landscape Studies, 10(2), 75-81.

Kerrigan, P. (2009). "Resisting Darwin: the natural theological design philosophy of Gertrude Jekyll", Studies in the History of Gardens \& Designed Landscapes, 29(4), 314-329.

Kingsbury, N. and Oudolf, P. (2010). Landscape in landscape. London: Thames \& Hudson.

Lord, T. (1995). Best borders, Frances Lincoln Limited, London.

Mahmoud, A. H., \& Omar, R. H. (2015). "Planting design for urban parks: Space syntax as a landscape design assessment tool", Frontiers of Architectural Research, 4(1), 35-45.

Malgorzata, S. (1991). "Effects of pre-harvest supplementary irradiance on decorative value and ethylene evolution of Campanula carpatica "Karl Foerster” flowers", Scientia Horticulturae, 48(3-4), 341-347.

Park, E. (2015). "Design of the Seoul Artisan Garden-Cultural Heritage of the Artisan and Its Spatial Representation", Journal of Recreation and Landscape, 9(4), 101-109.

Provan, K. G., \& Milward, H. B. (1995). "A Preliminary Theory of Interorganizational Network Effectiveness: A Comparative Study of Four Community Mental Health Systems", Administrative Science Quarterly, 40(1), 1-33.

Scott, N., Baggio, R., \& Cooper, C. (2008). Network analysis and tourism: From theory to practice. Network Analysis and Tourism: From Theory to Practice. Channel View Publications.

Scott, J. (2000). Social network analysis: A handbook. 2nd edtion, Sage, London.

Sepahi, A. (2000). "Nature as a model for large-scale planting design", Landscape Research, 25(1), 63-77.

Simo, M. L. (1985). "William Robinson, 1838-1935: Father of the English flower garden by Meg Allan; A century of gardeners by Betty Massingham; John Dobson: Architect and landscape gardener by Lyall Wilkes", Victorian Studies, 28(2), 334-336.

Wasserman, S., \& Faust, K. (1994). Social network analysis: Methods and applications (Vol. 8), Cambridge university press, Cambridge.

Waymark, J. (2003). Modern garden design, Thames \& Hudson, London.

Zoh, K.-J. (1994). Re-inventing gardens: a study in garden theory, Doctoral thesis, Pennsylvania University. 